\title{
Los historiantes de Huertas: La danza de los Moros y Cristianos
}

\author{
The historiantes* from Huertas: The dance of Moors \\ and Christians (danza de Moros y Cristianos) \\ DOI: https://doi.org/10.5377/koot.v0i11.10741 \\ URI: http://hdl.handle.net/11298/1197
}

Reynaldo Antonio Rivas

Catedrático de Ética y Filosofía

Universidad Tecnológica de El Salvador

rivasreynaldo@gmail.com

\section{Resumen}

Fecha de aceptación: diciembre 2020

El presente artículo de tipo etnográfico presenta la bicentenaria tradición de la danza de los Moros y Cristianos, del grupo de Los Hsistoriantes del Cantón las Huertas, Ilobasco, Cabañas, El Salvador. El estudio fue realizado en el año 2019. Iniciando en junio con las primeras visitas exploratorias se constató que el grupo de Historiantes estuvo inactivo durante 15 años. Al concluir el estudio, en diciembre, se logró la reactivación del grupo, gracias a que aún viven 6 integrantes que recibieron la tradición por transmisión oral directa. Ahora ellos transmiten la tradición a una quinta generación de Historiantes en el referido cantón.

Palabras claves: Culturas tradicionales - Las Huertas, Ilobasco, Cabañas, El Salvador. Danza (en religión, folklore, etc.). Danzas populares y nacionales salvadoreñas. Antropología cultural - Historia - Las Huertas, Ilobasco, Cabañas, El Salvador. Folclor - Las Huertas, Ilobasco, Cabañas, El Salvador. La danza de los Moros y Cristianos - El Salvador

\begin{abstract}
This ethnographic article introduces the bicentennial tradition of the dance of Moors and Christians (danza de Moros y Cristianos), from the group Los Historiantes* in Cantón las Huertas, city of Ilobasco, department of Cabañas, El Salvador. The study was conducted during 2019, and the initial exploratory visits took place in June; one of the findings during these visits was the fact
\end{abstract}


that the group of historiantes had been inactive for 15 years. When the study concluded in December, the reactivation of the group had been achieved thanks to the collaboration of 6 surviving members who learned about this tradition via direct oral tradition. At present, they are in charge of transmitting this tradition to a fifth generation of historiantes in said cantón (small countryside town).

historiante*(dancer or participant in the representation of moors and christians).

Key words: Traditional cultures - Cantón Las Huertas, Ilobasco, Cabañas, El Salvador. Dance (in religion, folklore, etc.). Salvadoran popular and national dances. Cultural anthropology - History - Cantón Las Huertas, Ilobasco, Cabañas, El Salvador. Folklore - Cantón Las Huertas, Ilobasco, Cabañas, El Salvador. The dance of the Moors and Christians - El Salvador

\section{El origen de la danza}

Moros y cristianos o Historiantes son las expresiones que se utilizan para identificar las danzas tradicionales a través de las cuales se hace referencia a conflictos entre los musulmanes (moros) y los reyes cristianos ibéricos por aspectos religiosos. La tradición de los moros y cristianos inició en los países ibéricos (España y Portugal), conmemorando la época histórica de la lucha entre los cristianos y los árabes (moros) que duró casi 800 años, desde 711 hasta 1492. Por el fervor de celebrar una victoria, iniciaron la tradicional celebración extendiéndola a lo largo de los pueblos que conforman España y Portugal, pero el fervor festivo se concentra en Valencia y Alicante.

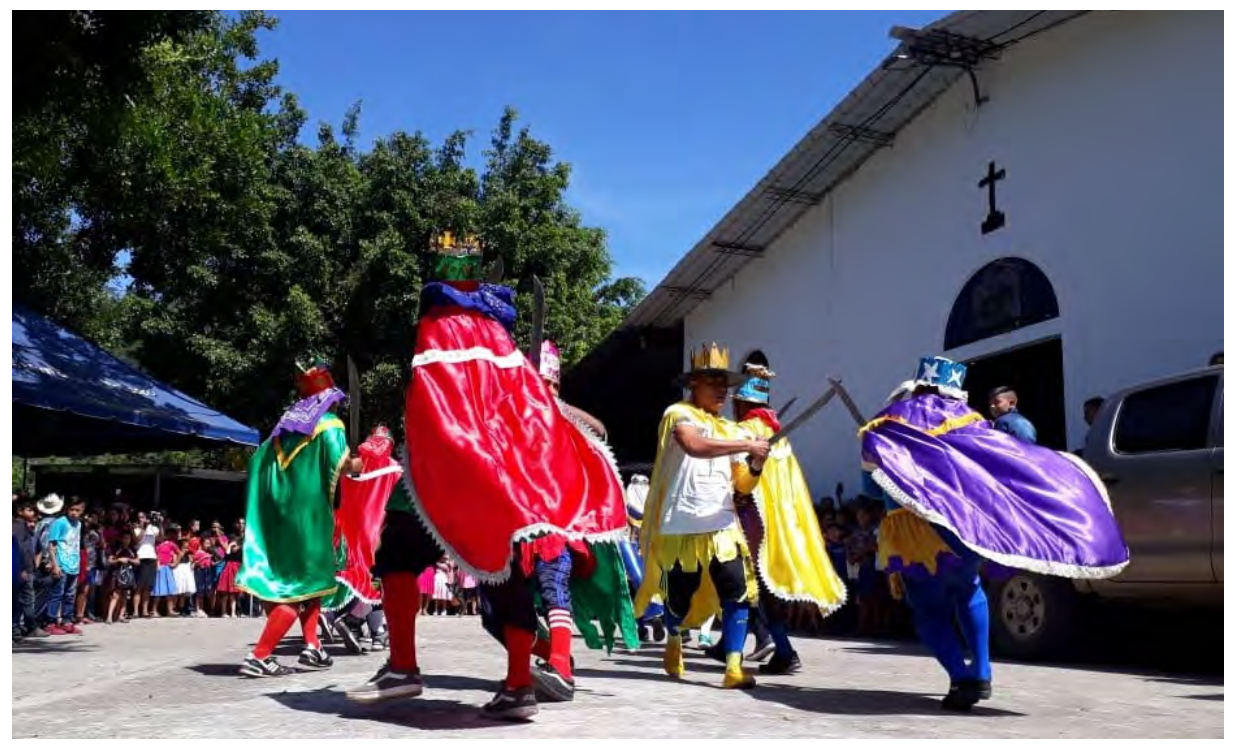

Figura 1. Danza de los Historiantes de Huertas 10 de noviembre de 2019.

Fotografía tomada por el autor 
De acuerdo a las aportaciones de la investigación de Pleités (2000),

Los bailes de los historiantes, apuntan que esta danza es producto de la época medieval (476-1453), llevada por los Árabes que llegaron a la región de Hispania en donde ejercieron una presencia de cerca de ocho siglos en la penín- sula. Las luchas por la reconquista del poder de los cristianos, auxiliados por la Santa Inquisición y la figura marcial del Patrón Santiago, fueron su inspi- ración. Por ello, se sostiene que sus orígenes se encuentran en la dominación musulmana en España (771-1002), en donde la primera referencia documental de la danza se vincula a la boda del Conde de Cataluña, Ramón Berenguer IV, con Petronila, Reina de Aragón. Esta fue celebrada en la Catedral de Lérida en el año de 1150. En esa boda se fingió un combate entre moros y cristianos.

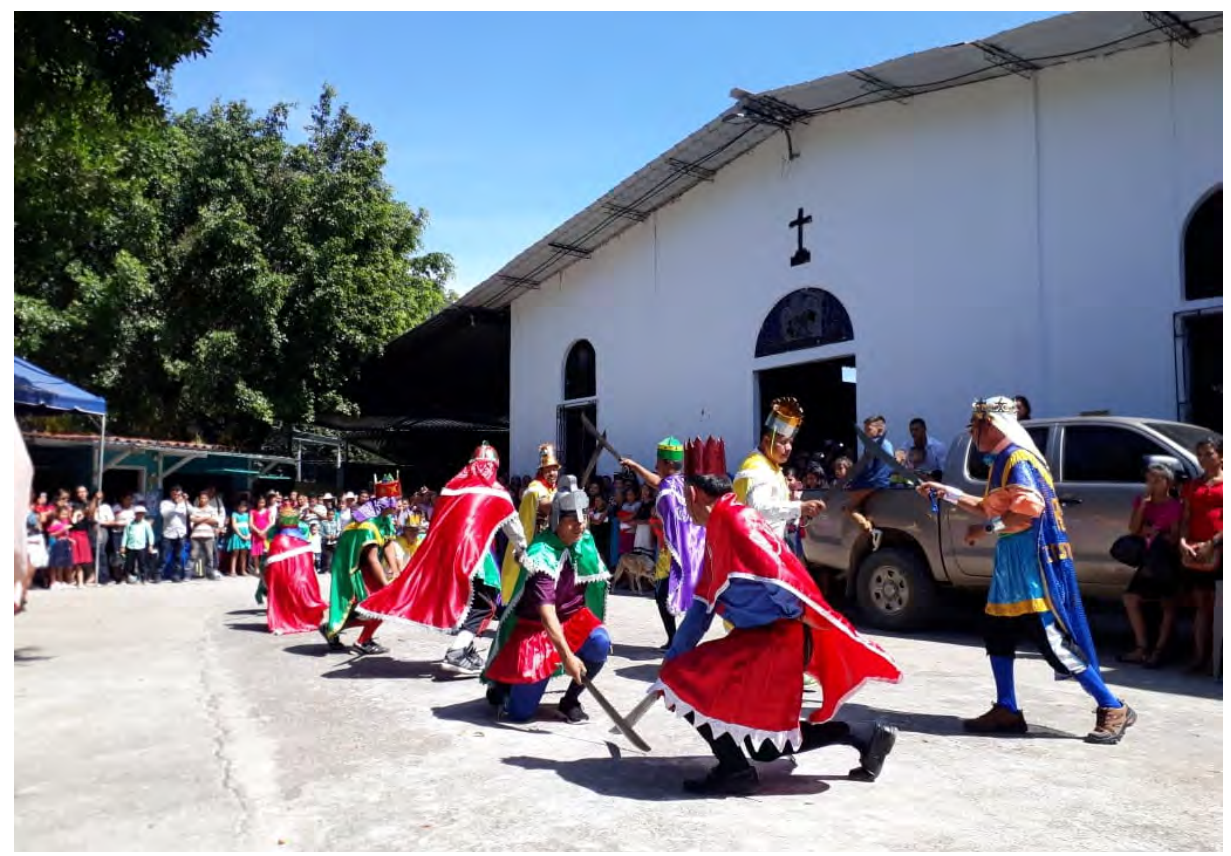

Figura 2. Danza de los Historiantes de Huertas 10 de noviembre de 2019.

Fotografía tomada por el autor

En nuestro país, la historia de la danza se remonta a los tiempos mismos de la Colonia. Ésta fue utilizada como método de evangelización, pero también como método de aculturación de los pueblos originarios, quienes la terminaron adoptando con variantes específicas. "Una hipótesis sustenta que los curas enseñaron las historias a los indígenas para que formaran los grupos de danzantes y digirieran que el cristianismo es todopoderoso, tanto como para vencer a los musulmanes" (Martínez, 2016), mientras que otra indica que estas danzas fueron introducidas con la idea de doblegar a los indígenas por medio de es- 


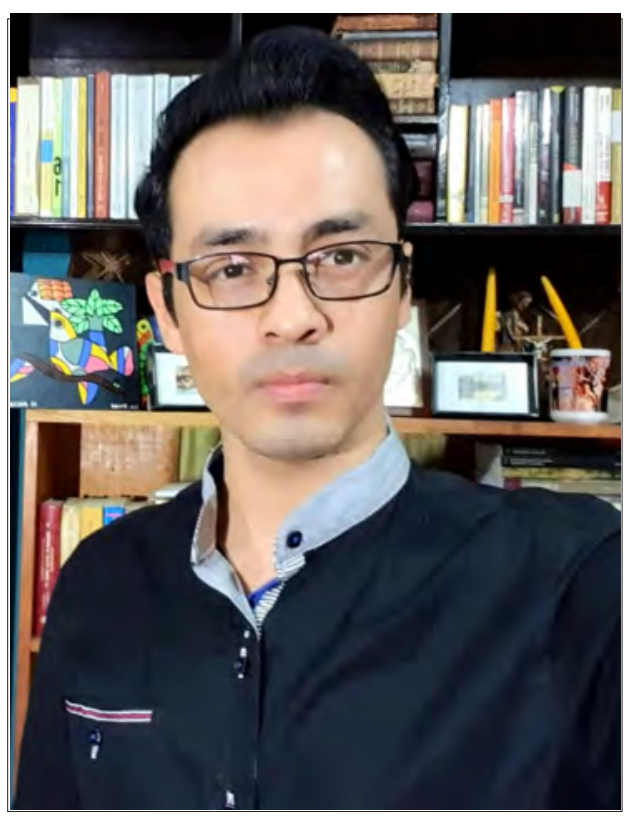

Reynaldo Antonio Rivas

tas representaciones confeccionando nuevos argumentos y teniendo una carga ideológica-religiosa porque acentuaban la lucha del bien contra el mal (el bien representado por los cristianos, o sea los españoles cristianizados o indígenas bautizados y el mal representado por los moros).

Así pues, en nuestro país, la danza tiene su origen con la llegada de los españoles a Cuscatlán, siendo una mezcla de la cultura de los indios cuscatlecos y la cultura de los conquistadores que llegó a borrar casi todo vestigio de las danzas tradicionales indígenas dando como resultado una nueva cultura híbrida, más que un proceso de transculturación (Vela, 2007).

\section{Los historiantes en el territorio salvadoreño}

En el país y muchos otros países de américa latina celebran fiestas anuales donde enriquecen su espectáculo con danzas tradicionales. Esto se debe a que durante la conquista española y la época de la colonización también se fomentaron nuevas creencias y especialmente con el tema de la religión; por lo tanto, también se dio inicio a la adaptación de costumbres por parte de nuestros pueblos y una de ellas fue la Danza de los Moros y Cristianos.

La manera como se establecen Los Historiantes en la cultura del pueblo no es suficientemente clara. Según los estudios realizados por Martínez (2019) para la elaboración de un mapa de moros y cristianos en El Salvador, identifica 
32 grupos de historiantes en 31 municipios del país, abarcando el 11.8\% de los municipios del territorio nacional. Entre los 32 grupos identificados están los Historiantes del Cantón Las Huertas, en el municipio de Ilobasco, Departamento de Cabañas.

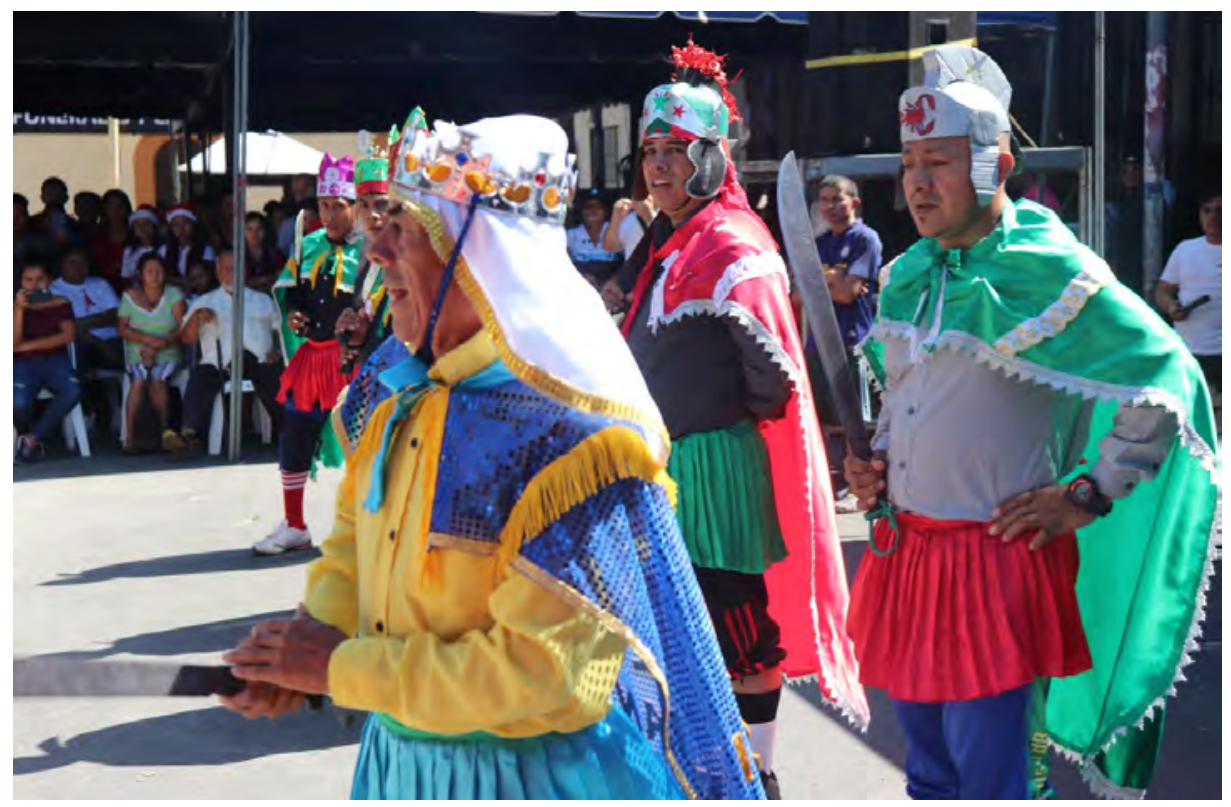

Figura 3. Danza de los Historiantes de Huertas 10 de noviembre de 2019.

Fotografía tomada por el autor

\section{Los historiantes de Huertas}

\section{El cantón las Huertas: una descripción}

El cantón Las Huertas es uno de los 18 cantones de la ciudad de Ilobaso. Se encuentra ubicado a 10.2 kilómetros al noreste de la ciudad. Posee una topografía de empinados cerros, altos acantilados, terrenos pedregosos; pequeñas quebradas y riachuelos que surcan abundantes de agua en el invierno y casi extintos en el verano. Todas las quebradas desembocan en el río que toma nombre de cada caserío que atraviesa. Así, en la parte alta el río se llama el roble y en la parte baja se convierte en el río La Veguita o Las Vegas. Este río sirve de límite natural con el cantón el Potrero.

El cantón está compuesto por seis caseríos: El Centro, El carrizal, Arenera, Mundo nuevo, El Jícaro, e Isletas. 
Los límites del cantón las Huertas son: al Noroeste limita con Azacualpa; al Noreste con San José Calera y, al Sur con cantón El Potrero.

Según el censo poblacional llevado a cabo por la Parroquia Sagrado Corazón de Jesús, del cantón Las Huertas (2019), el cantón tiene una población de 1,754 habitantes.

La economía del cantón depende, en su mayor parte, de las remesas. La agricultura es bien básica: cultivan frijoles y maíz. Y, a diferencia de los demás cantones de Ilobasco, en las Huertas no se da la Ganadería.

\section{Los orígenes del cantón}

Si bien es cierto, no podemos reconstruir, con documentación escrita sobre el tema, la historia remota de los orígenes del cantón las Huertas, sí podemos encontrar datos que sugieren la existencia de este cantón en los orígenes mismos de la población que habitaba Sitio Viejo y que, más tarde, conformaría Ilobasco. Por tanto, si Sitio Viejo estaba ya habitado por una pequeña población hacia finales del 1500, podemos decir lo mismo de Huertas. En efecto, con respecto al origen de la población de Ilobasco, la historia se remonta a la época precolombina, a finales del año 1500. Esta ciudad fue fundada por tribus Lencas, a principios de 1600, con estrechos vínculos comerciales con Chortíes e indígenas y estos a su vez tuvieron que compartir el lugar en épocas posteriores con Pipiles del habla Náhuat (Proyecto de Fortalecimiento de Gobiernos Locales 2014, p. 14).

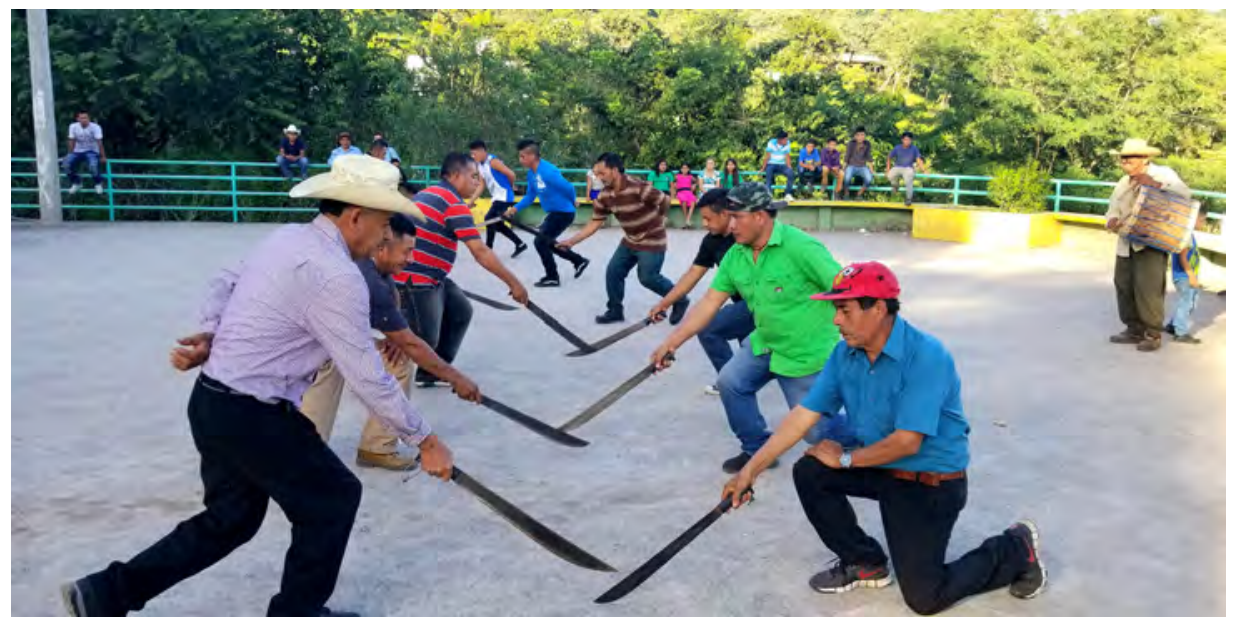

Figura 4. Ensayo de los historiantes 8 de noviembre de 2019

Fotografía tomada por el autor 
Algunos datos que atestiguan la existencia del cantón las Huertas:

- En el año 1620, los frailes Dominicos, quienes administraban en lo religioso la zona, hicieron una peregrinación con la Imagen de San Miguel Arcángel, por los cantones que hoy conforman Ilobasco. Y fue entre los indígenas del actual cantón Las Huertas, en donde los frailes tuvieron mucha aceptación y muy pronto pasaron a convertirse en soldados del patrón San Miguel (Rivas 2000, p. 261).

- Según Rivas (2000), “en otros tiempos existieron caleras fuera de la ciudad, precisamente en los cantones Las Huertas y San José Calera”. (pp. 106-107)

- Para el año 1858, Lorenzo López describe en su informe la existencia en Ilobasco de tres haciendas dedicadas al cultivo del añil y la crianza del ganado; y además, se encuentran los caseríos siguientes: Cerro Colorado, Azacualpa, San José Oratorio, Sitio Viejo, Los Llanitos, [...], Calera y Huertas (López, 2010)

El dato más interesante, para nuestros fines, es la datación de la peregrinación de San Miguel Arcángel en el año 1620 y la consecuente creación de un grupo en torno al Santo Patrono. De hecho, a juicio de Rivas (Rivas, 2000, pp. 261-262), el grupo de Historiantes hunde sus raíces remotas en ese grupo de Soldados del patrón San Miguel".

\section{El santo patrono: San Miguel Arcángel}

Siguiendo la sugerencia de Rivas (2000) y escuchando a los pobladores en visita de campo, así como también, teniendo en cuenta la tradición religiosa de la Iglesia católica del lugar, consta que los pobladores de Huertas guardan profundo respeto y devoción por la Imagen de San Miguel Arcángel (p. 261)

La razón histórica la encontramos en la peregrinación hecha por los frailes dominicos en 1620, con la Imagen de San Miguel, y la consecuente formación de los "Soldados del patrón San Miguel". Los Huerteños - como se les conoce - se identificaron fuertemente con la advocación. Sin embargo, como la Imagen estaba resguardada en el templo parroquial en la ciudad de Ilobasco, los Huerteños luchaban por tenerla con ellos en su cantón. De algún modo, se identificaban como los custodios de la Imagen y la devoción.

Nació así, a mediados de 1700, un ciclo de pleitos entre los Huerteños y los de la ciudad de Ilobasco por tener la Imagen. Estos pleitos declinarían cuando la Imagen les fue entregada. El antropólogo Ramón Rivas describe la situación de la siguiente manera: 
Para evitar los continuos pleitos con los habitantes del cantón Las Huertas por la Imagen de San Miguel Arcángel, los que, desde mediados de 1700 , a menudo llegaban al poblado reclamando la pertenencia de la Imagen y enfurecidos, al no ser escuchados, realizaban estragos en el lugar, el Presbítero Aquilino Herrera, un año después de haber tomado posesión como párroco en 1849 decidió darles la Imagen a "los huerteños con la condición de que le dieran la debida veneración y respeto". Con esta decisión y con ello llevándose de una vez la imagen para la ermita de Las Huertas, se terminaron muchos años de terror en la ciudad por parte de tan temidos habitantes. [...]

En las Huertas todo fue bien hasta que, por descuido, o por mala intención, sucedió lo que nadie se esperaba con tan venerada imagen. De acuerdo al Dr. Vicente Navarrete: "La imagen de San Miguel era de madera y hecha con verdadero arte; fue incendiada junto con su nuevo altar y una parte de la ermita, de manera contingencial, el 17 de mayo de 1934 en el cantón Las Huertas de la misma jurisdicción, lugar donde era verada desde hacía muchísimos años". [...]

No obstante, "los huerteños" aún hoy en día, son aferrados devotos de San Miguel Arcángel y siempre recuerdan la fecha de "la desgracia del incendio (...)”. (Rivas, 2000, pp. 262-263)

El 13 de enero de 2016, el cantón las Huertas fue erigido como Parroquia por decreto del Obispo de la Diócesis de San Vicente, Mons. José Elías Rauda. El territorio que le pertenece fue desmembrado de la Parroquia San Miguel Arcángel de Ilobasco. De este modo, la jurisdicción de la nueva parroquia abarca: Isletas, Santa María de los Milagros, el Jícaro, Quebrada Honda, San José Calera, Vista Hermosa, Las Vegas y las Flores. Su sede está en el caserío El Centro, de Huertas. El primer párroco (2016-2019) fue el Pbro. José Gregorio Beltrán. Actualmente la preside el Pbro. Rosario Eliseo Rivas. En cada caserío hay ermitas que son atendidas por el sacerdote párroco de la parroquia.

Las fiestas patronales, históricamente se celebran en honor a San Miguel Arcángel, del 21 al 29 de septiembre. Pero, cuando se erige como Parroquia, se dispuso como patrono al Sagrado Corazón de Jesús, con fecha movible cada año: se festeja el viernes posterior al segundo domingo de Pentecostés. Pese a ello, al centro del retablo del Altar del templo parroquial, está la imagen de San Miguel Arcángel, como prueba de la profunda fe y veneración que los huerteños tienen por su Santo Patrono. 


\section{La historia de los Historiantes de Huertas}

La transmisión oral de la tradición de los Historiantes con su danza, en Huertas, tiene sus raíces en los Historiantes de Izalco, hace ya más de 200 años. Era el tiempo en que las personas que habitaban Huertas iban hasta el occidente del país a trabajar para los hacendados.

Según refiere un informante, fue don Juan Vásquez el primero que llevó la danza a Huertas:

Él había ido a trabajar a Izalco, allá vio y aprendió la danza y las retahílas, las poesías y las trajo al cantón donde se las enseñó a otros. Él estaba joven y se las sabía de memoria porque en Izalco las estudió del libro que allá tienen. Don Juan - me contaban mis abuelitos - que bailó hasta que ya estaba bien ancianito. Por lo menos le calculo unos 60 años que él fue Rey (Reyes, 2019).

Después de don Juan Vásquez (primera generación), los ensayadores y Reyes fueron los siguientes: Margarito Vásquez y Santiago Romero (segunda generación); Brígido Reyes y Dionisio Reyes (tercera generación).

A juicio de los informantes, cada uno de ellos danzó entre 50 y 60 años, pues todos han iniciado a danzar cuando eran adolescentes o jóvenes:

Cuando ya uno puede manejar bien el corvo, y como uno desde chiquito anda, aunque sea un garrote en la mano, uno está acostumbrado. Entonces cuando comenzaron a danzar, estos viejitos tenían por lo menos 18 o 20 años y danzaron unos 60. Para el tiempo de don Brígido y Dionisio Reyes - que eran nuestros abuelos - un señor llamado don José Alemán, que vivía en las Minas tenía un librito donde estaba la historia de Carlos Magno o también llamada los doce Pares de Francia. Yo todavía vi ese librito, pero se perdió. De ese librito nos aprendimos de memoria la historia (Reyes, 2019).

La cuarta generación de ensayadores y Reyes la representan don Manuel Reyes y don Leonardo Reyes. Don Manuel representa al Rey Moro Almirante Balán y, don Leonardo, al Emperador Cristiano Carlos Magno. Ellos llevan ya 48 años danzando.

De modo que, si quisiéramos establecer un dato cronológico, la información cierta por transmisión oral, refiere que el grupo de Historiantes del cantón Las Huertas tiene entre 200 y 230 años de existencia. Sin embargo, los últimos 
15 años habían permanecido inactivos por varios motivos. Los informantes refieren que:

la gente no entendía por qué peleamos con los corvos, y como también después trajeron a los viejones y payasos para el desfile de las fiestas, ya no quisieron que saliéramos nosotros. Además, hubo un sacerdote que nos dijo que no quería saber nada de esto, que él no estaba de acuerdo. Y como a los jóvenes de hoy no les interesa, por todo eso nos fuimos quedando (Reyes, 2019).

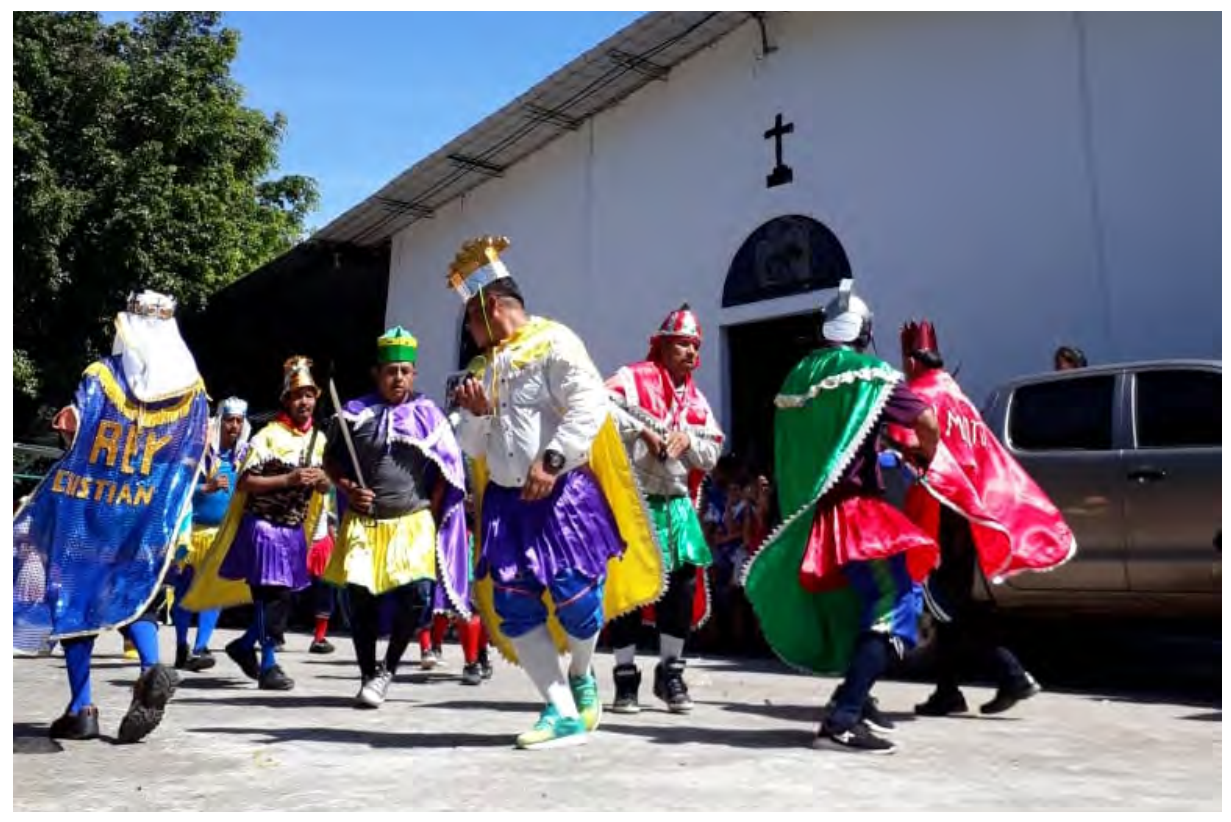

Figura 5. Danza de los Historiantes de Huertas 10 de noviembre de 2019.

Fotografía tomada por el autor

Pese a todo, aún hoy hay vivos 6 de los 12 integrantes de la cuarta generación. Ellos se han encargado de transmitir y ensayar y danzar con otros que llevan menos tiempo con ellos: los mayores llevan más de cuarenta años danzando, otros entre quince y veinte y, los más jóvenes son los que se han incorporado recientemente.

El grupo de Historiantes volvió a danzar el domingo 10 de noviembre de 2019 en el atrio de la ahora Parroquia Sagrado Corazón de Jesús, en el Cantón Las Huertas, ante la presencia de más de un centenar de personas de los caseríos aledaños. En esta ocasión, presentaron la Historia de Carlos Magno. 


\title{
La Historia de Carlos Magno
}

Los Historiantes de Huertas conocen a memoria la historia de Carlos Magno. No hay un texto escrito, por tanto, la transmisión oral ha sufrido algunas modificaciones. Hay palabras de difícil comprensión. Aquí las transcribimos tal como los integrantes nos las han referido verbalmente.

La Historia refiere el encuentro del Rey Almirante Balán con el Emperador Carlos Magno. Es el Rey Moro quien provoca al Emperador Cristiano con estas palabras:
Oh emperador Carlos Magno
hombre cobarde y sin ninguna virtud
envía dos o tres o cuatro de tus varones
a un hombre solo que espera batalla, aunque sea Roldán y Olivero
titere y ojer de la noy
que te juro por mis dioses
que no les volverás a ver las caras;
$¿ 0$ habéis por ventura olvidado el pelear
o te hace miedo de mi lanza?
Venid, venid los doce pares,
que uno solo no osa.

Entonces, del ejército Cristiano, Guarín se presenta ante Carlos Magno y le dice:

\author{
Señor, \\ te suplico me des licencia de responderle a Fierabrás \\ pues ya que muchas veces te ha llamado \\ y si en esto será mi servicio \\ bien galardonado. \\ Responde Carlos Magno: \\ No, \\ ese hombre es un gran guerrero
}

Entonces, todos concuerdan que debe hacerse la batalla. Ésta se organiza. Después de un preludio de danza en la que los corvos resuenan al son del pito y del tambor, cada uno de los guerreros, comenzando por los Moros encabezados por su Rey, dice su poesía, en el siguiente orden: 


\begin{tabular}{|c|c|}
\hline Moros & Cristianos \\
\hline $\begin{array}{l}\text { 1. Rey Moro, Almirante Balán: } \\
\text { Oh emperador Carlos Magno: } \\
\text { ¿a dónde estás? } \\
\text { pues a la Turquía entraste } \\
\text { en busca mía } \\
\text { sólo por topar contigo } \\
\text { y vengarme en tu persona } \\
\text { pues con grande honra sería. } \\
\text { Y con esa tu imperial corona } \\
\text { y con tus propias manos } \\
\text { me amediaces a muerte, } \\
\text { pero primero bañaré mi espada en tu sangre } \\
\text { delante de ese viejo cano, } \\
\text { pues no hallaré piedad en los tuyos } \\
\text { ni menos la encontraréis en mí. }\end{array}$ & $\begin{array}{l}\text { 1. Emperador Carlos Magno: } \\
\text { Oh valerosos capitanes } \\
\text { en vuestro valor confío } \\
\text { para provocar al moro } \\
\text { y llamarlo al desafío. } \\
\text { Pues soy valiente siciliano } \\
\text { flor de las caballerías } \\
\text { que son espejos de justicia } \\
\text { en quien él mismo se mira. } \\
\text { Hoy es cuando, que todo } \\
\text { en guerra y su bizarría } \\
\text { para que mueran magnetas } \\
\text { quiero darles batería. } \\
\text { Pues para hoy quiero el valor } \\
\text { que oscita mi pecho ardiente } \\
\text { contra este bárbaro activo } \\
\text { confiado en Dios todopoderoso } \\
\text { y en la gloriosa Virgen Santa } \\
\text { María, la victoria ganaremos } \\
\text { Todos: ¡Ganaremos! }\end{array}$ \\
\hline $\begin{array}{l}\text { 2. Sostibrían, Guerrero: } \\
\text { Soy Sostibrián guerrero } \\
\text { azote de los cristianos } \\
\text { con mi opinión y valor } \\
\text { es causa del imperio; } \\
\text { y todos esos viles cristianos } \\
\text { vendrán a morir a mis pies. }\end{array}$ & $\begin{array}{l}\text { 2. Roldán, el valiente: } \\
\text { Yo soy Roldán, el valiente } \\
\text { que he salido a esta campaña, } \\
\text { pues a mí nadie me engaña; } \\
\text { con el puñal en mis manos } \\
\text { le digo a mis compañeros } \\
\text { que seamos valientes guerreros; } \\
\text { yo mato a ese embustero } \\
\text { que está en el magno sagrado, } \\
\text { y aunque así sean mil moros } \\
\text { no me ajustan ni a bocado. }\end{array}$ \\
\hline
\end{tabular}


3. Fierabrás de Alejandría:

Soy el mentado tacuazín pasando por una quebradera pues cuando yo me enojo, no respeto ni a mi abuela.
3. Olivero ((nombre real, pero usa el de Guarín para despistar):

Yo soy Guarín el valiente de la ciudad de Lorena, con esta mi espada buena y mi valor prominente, pues para mí no hay valiente que me pueda resistir; ya tienen la muerte patente, pues ya se va a morir.
4. Burlante (Caparrote):

Sale Burlante dice:

estrella de mar que brota con este mi cortante cuchillo la vida les voy a cortar.

\section{Ricarte de Normandía:}

El enviar una embajada

no es preciso en este día, avisándole a sus hombres que se preparen a la riña.

\section{Valiente Salín:}

Como valiente Salín general de tu escuadrón con mi brillante corvo, destruiré al Rey Español.

\section{Luis de Gorgona:}

Vaya pues don Santiago, antes de entrar al castillo no los vayan a pelar como quien pela a una gallina.

\section{El Gracioso:}

Todos, todos policías todos, todos han hablado y esto de pelear con los cristianos no es como comer tortillas.
6. El Gracioso:

El chiquito y el grandote con este mi corvote me voy a hacer mamasos a esos caras de jolote.

\section{La música de los historiantes}

Los historiantes de Huertas acompañan su danza al son del pito y el tambor. El pito está hecho de vara de carrizo y el tambor de madera y cuero de venado, ajustado con coyundas de cuero y pitas. El ritmo es acompasado y emula el sonido de la guerra. Va en crescendo en los momentos más intensos de la escenificación de la batalla y en los interludios cuando cada pareja de guerreros está danzando. Los corvos chocan en el aire y rosan por el suelo resonando armónicamente. El pito y el tambor callan cuando cada guerrero va a recitar su retahíla. Resulta particularmente melódica la pieza de salida cuando los danzantes se retiran. En efecto, el tambor reproduce el tropel de los caballos sobre calles empedradas y el pito el son de la victoria. 


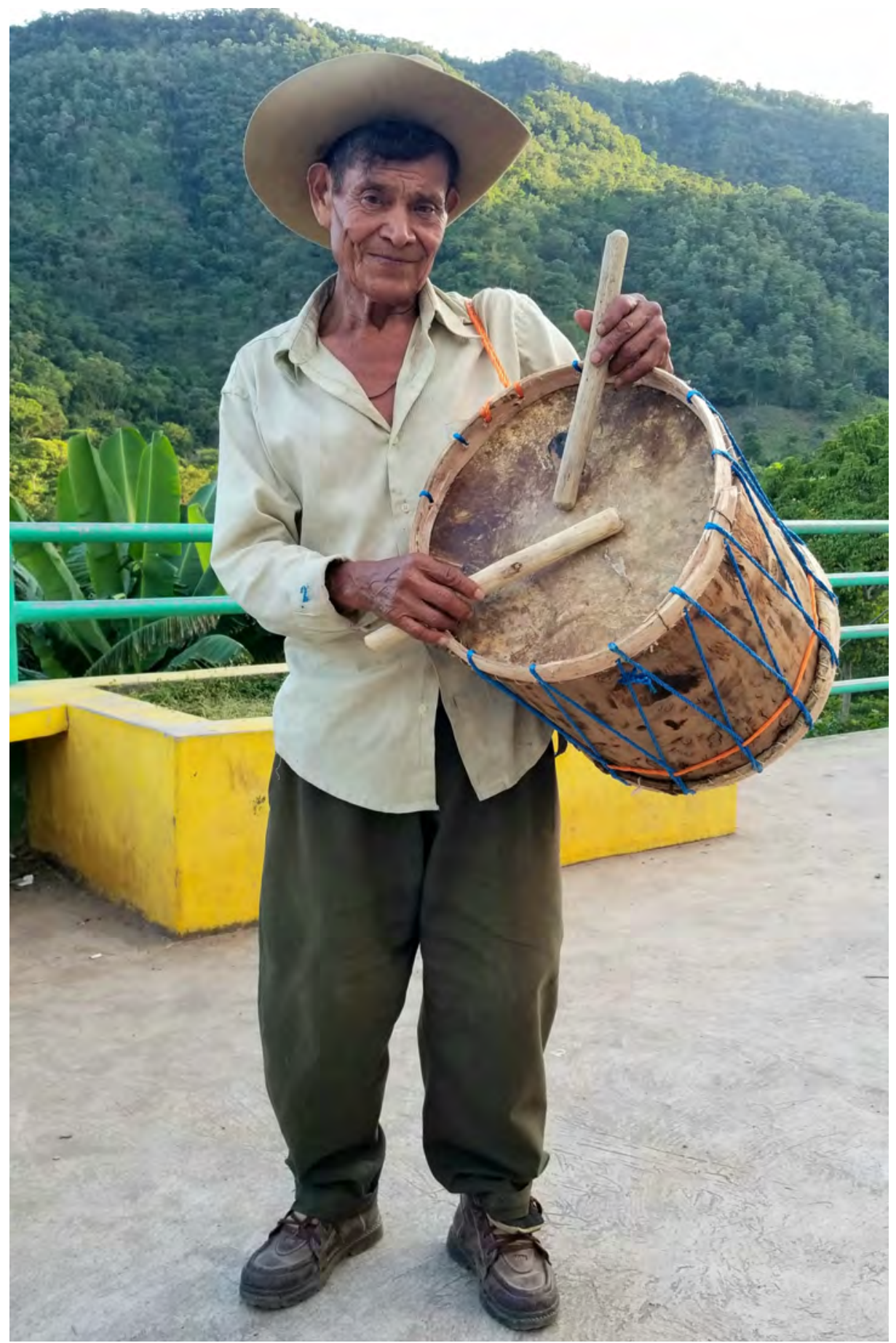

Figura 6. Danza de los Historiantes de Huertas 10 de noviembre de 2019.

Fotografía tomada por el autor 


\section{El vestuario de los historiantes}

A nivel general (Martínez Rivera, 2015), la vestimenta que se utilizan para quienes representan a los cristianos tiene los siguientes elementos: las máscaras que son un elemento europeo (todas ellas con rasgos de hombres blancos barbados, de bigote, ojos claros y algunos de cabellos rubios), coronas adornadas con flores, pantalones sencillos y trajes de guerreros cruzados.

Los moros portan una vestimenta más elaborada, siendo que llevan plumas, cascos de figuras zoomorfas, en algunos casos portan monedas antiguas, un pequeño delantal, una capa y sobre ella una de forma cuadrada; los colores brillantes están presentes en las vestimentas haciéndolas más llamativas.

Ambos utilizan también figuras de papel de estaño, bordados y artículos brillantes.

Los historiantes de huertas, refieren que históricamente así lo hacían, pero que cada miembro dispone de su traje según sus posibilidades. En la presentación que tuvieron al término de esta investigación, no portaban máscaras, pero sí sus trajes elaborados, sus coronas y, ciertamente, el corvo como representación de la espada.

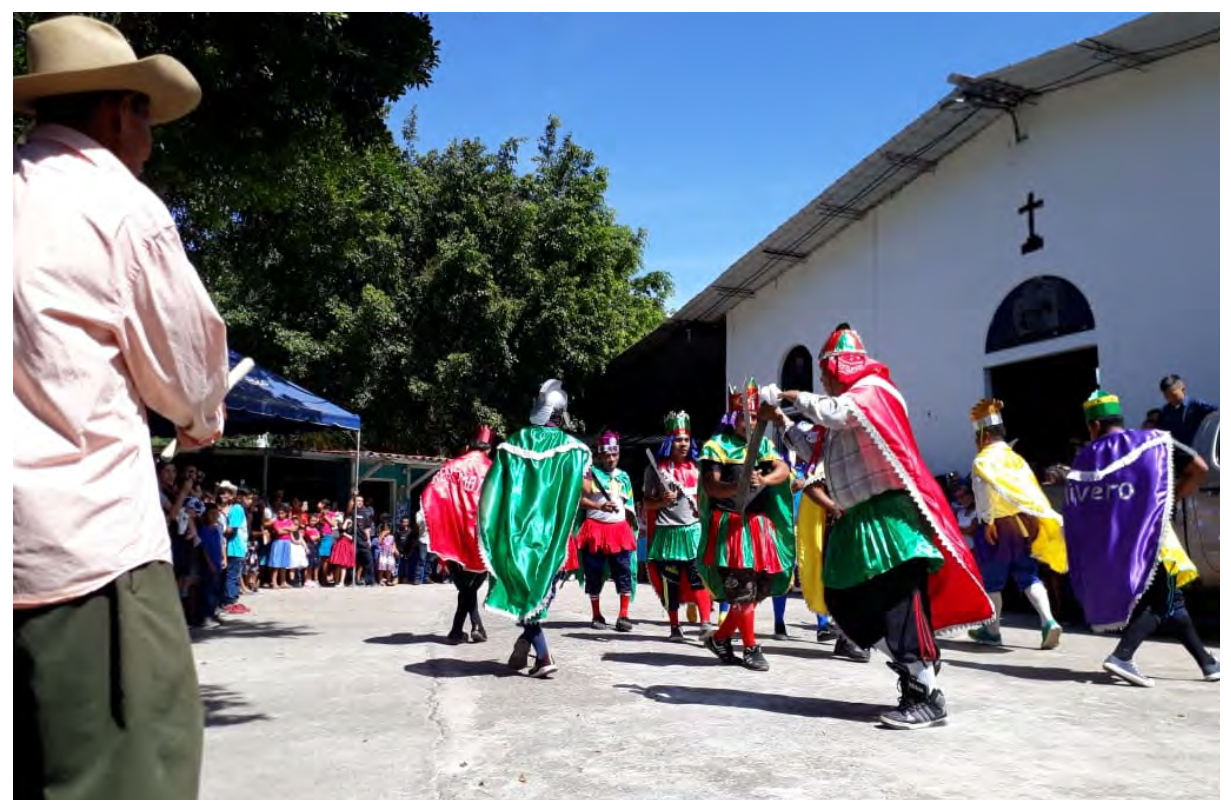

Figura 7. Danza de los Historiantes de Huertas 10 de noviembre de 2019.

Fotografía tomada por el autor 


\section{Por una valoración conclusiva}

Los factores históricos que propiciaron el encuentro de las culturas originarias con las europeas, fusionaron elementos que dieron como resultado el nacimiento de distintas tradiciones en nuestros pueblos. Muchas de esas tradiciones han perecido en el tiempo; otras tantas perduran hasta el día de hoy, en sus distintas y variadas expresiones.

Los pobladores del Cantón Las Huertas tienen una rica y larga historia, que hunde sus raíces a los tiempos anteriores a la Colonia. Huertas era paso de las tribus Chortis que venían desde Honduras a comercializar con los Lencas de Ilobasco e iban hasta San Vicente.

La tradición de los Historiantes resulta ser bicentenaria, y ha tenido adaptaciones que responden al lugar. Por desgracia, ha sufrido un largo periodo de inactividad que casi la extingue. Sin embargo, en la memoria de los pobladores se mantiene viva la historia de "ese grupo de moros y cristianos que peleaba con los corvos" - como lo refiere un poblador. Esa memoria viva non-scripta ha hecho posible que grafiquemos ahora y se revitalice la tradición.

\section{Referencias bibliográficas}

Instituto Salvadoreño de Desarrollo Municipal ISDEM y Proyecto de Fortalecimiento de Gobiernos Locales PFGL. (2014). Plan estratégico participativo con énfasis en desarrollo económico, período 2015-2019. Municipio de Ilobasco, Departamento de Cabañas. Recuperado de www. trasnpeencia.gob.sv

López, A. (05 de noviembre del 2010). Ilobasco mi tierra...by Norberto López [Entrada en el blog]. Recuperado de http://jesusfreak-jff17.blogspot. com/2010/11/ilobasco-tierra-de-artesanos.html

López, L. (1926). Estadística general de la República de El Salvador 1858.

San Salvador, El Salvador: Dirección de Publicaciones del Ministerio de Educación.

Martínez Rivera, J. C. (2016). Moros y cristianos Los historiantes en el imaginario salvadoreño. Revista de museología Kóot, 6(7), 118-132. doi: doi.org/10.5377/koot.v0i7.2986

Martínez Rivera, J. C. (2016). Moros y cristianos Los historiantes en el imaginario salvadoreño. Revista de Museología Kóot, 6(7), 118-132.

Martínez Rivera, J. C. (2019). Moros y cristianos: Hacia un mapa conceptual $y$ geográfico en El Salvador. Recuperado de https:/issuu.com/ juliomartinez1/docs/hacia_un_mapa_de_moros_y_cristianos

Parroquia Sagrado Corazón de Jesús, Cantón Las Huertas. Diócesis de San Vicente, El Salvador. Censo poblacional 2019. Archivo Parroquial. 
Pleités, M. (2000). V Congreso Centroamericano de Historia Universidad de El Salvador 18, 19, 20 y 21 de julio de 2000. La Danza de moros y cristianos: manifestación artística que se niega a morir con el paso del tiempo. Revista electrónica Theorethikos. Recuperado de http://www.ufg. edu.sv/ufg/theorethikos/octubre20/ponencia02.htm

Proyecto de Fortalecimiento de Gobiernos Locales. (2014). Municipio de Ilobasco. Departamento de Cabañas. Plan estratégico participativo (PEP) con énfasis en desarrollo económico período 2015 - 2019. Recuperado de www.trasnpeencia.gob.sv

Reyes, L. (2019). La historia de los Historiantes de Huertas. (R. A. Rivas, entrevistador) [notas de apuntes].

Reyes, M. (2019). La historia de los Historiantes de Huertas. (R. A. Rivas, entrevistador) [notas de apuntes].

Rivas R. D. (2000). Ilobasco: una aproximación histórica y antropológica. San Salvador, El Salvador: Universidad Tecnológica de El Salvador

Vela, V. (07 de enero del 2007). Los Historiantes de El Salvador. [Entrada en el blog]. Recuperado de http://historiantes.blogspot.com/2007/01/loshistoriantes-de-el-salvador.html 


\section{Pieza de Exposición}

Museo Universitario de Antropología

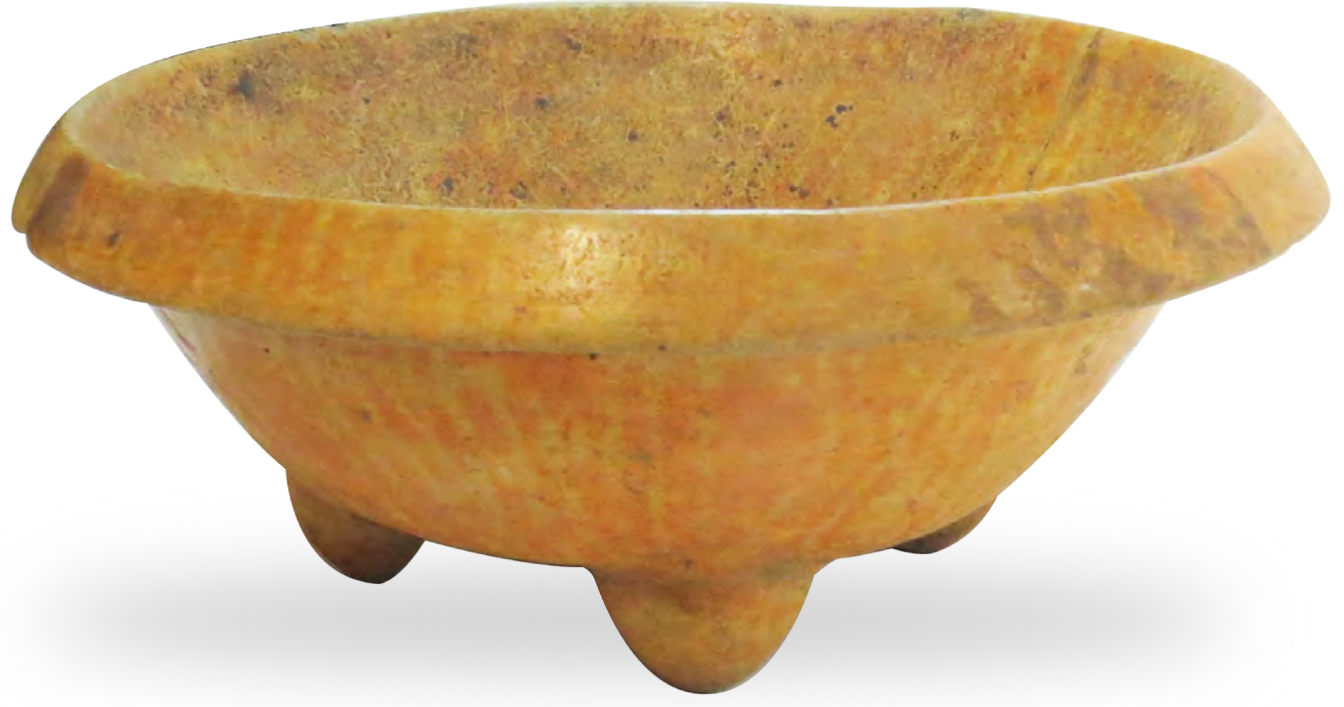

Cuenco

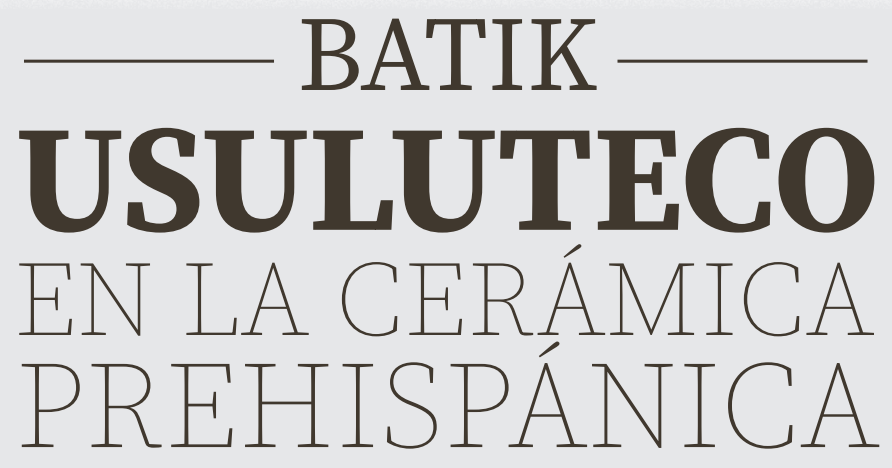

